\title{
Should I stay or should I go? Movement of adult Triatoma sordida within the peridomestic area of a typical Brazilian Cerrado rural household
}

Edson Santos Dantas ${ }^{1,2}$, Rodrigo Gurgel-Gonçalves ${ }^{3}$, Daniel Antunes Maciel Villela ${ }^{4}$ Fernando Araújo Monteiro ${ }^{2^{*+}}$ and Rafael Maciel-de-Freitas ${ }^{*^{*+}}$

\begin{abstract}
Background: Chagas disease, or American trypanosomiasis, is an important neglected tropical illness caused by the flagellate protozoan Trypanosoma cruzi, which is primarily transmitted to humans by hematophagous insects of the subfamily Triatominae. Although knowledge on triatomine movement capabilities at the micro-geographical scale is of fundamental importance concerning the development of effective vector control strategies, it remains a poorly understood subject. Furthermore, survival rates and size estimates of natural populations are important topics to consider when evaluating transmission intensity.

Results: The movement of adult Triatoma sordida within the peridomestic area of a rural Brazilian household was evaluated via mark-release-recapture assays. A total of 210 insects had their pronota marked with fluorescent dyes and were released at different distances from the chicken coop (two, five, ten and $20 \mathrm{~m}$ ), and from the horse corral $(27,32,35,46$ and 56 m). Recaptures occurred in three consecutive 15-day intervals. Specimens were successfully recaptured at all distances up to $32 \mathrm{~m}$. Bayesian models were used to estimate recapture probability, survival rates (males vs females) and population size. Although recapture probability was inversely proportional to distance for both sexes, females were more affected by increased distance. On the other hand, no significant difference was detected in the survival rates between males and females in a 15-day period. Fisher-Ford and Bayesian models gave more accurate population size estimates than Lincoln method.

Conclusions: Triatoma sordida adults were able to cover a distance of $32 \mathrm{~m}$ in 45 days. Recapture data modelling reveals that male dispersal was more effective suggesting that $T$. sordida males are more likely to contribute as potential colonizers of the peridomestic environment. Increasing the distance between the peridomestic structures and the sylvatic environment as much as possible appears to be a simple and feasible recommendation to reduce the contact rate between humans and infected bugs and ultimately Chagas disease transmission.
\end{abstract}

Keywords: Chagas disease, Movement, Dispersal, Vectorial capacity, Triatoma, Reduviidae, Trypanosoma cruzi

\footnotetext{
* Correspondence: fam@ioc.fiocruz.br; freitas@ioc.fiocruz.br

${ }^{\dagger}$ Equal contributors

${ }^{2}$ Laboratório de Epidemiologia e Sistemática Molecular, Instituto Oswaldo

Cruz, Fundação Oswaldo Cruz (IOC/ FIOCRUZ), Rio de Janeiro, Brazil

'Laboratório de Transmissão de Hematozoários, Instituto Oswaldo Cruz,

Fundação Oswaldo Cruz (IOC/ FIOCRUZ), Rio de Janeiro, Brazil

Full list of author information is available at the end of the article
} 


\section{Background}

Chagas disease, or American trypanosomiasis, is an important neglected tropical disease caused by the flagellate protozoan Trypanosoma cruzi. This pathogen is most commonly transmitted to humans via the contact of infected faeces of hematophagous insects of the subfamily Triatominae (Hemiptera: Reduviidae) with the host's mucous membranes $[1,2]$. Other modes of transmission that have recently received attention include blood transfusion and ingestion of contaminated fruit juices $[3,4]$. The former has led to the dissemination of the disease to developing countries where there is no transmission cycle, such as Spain and Japan [5, 6], and the latter has contributed to the generation of acute per os micro-epidemics in rural areas of northern Brazil [7].

Triatoma sordida (Stål, 1859) is the Chagas disease vector most frequently captured in the peridomestic environment in Brazil, particularly in areas where Triatoma infestans (Klug, 1834) has been eliminated by the Southern Cone Initiative $[8,9]$. Knowledge of triatomine dispersal capabilities is key to the understanding of population dynamics and vector control. Although there is information available on the genetic structure and dispersal capabilities of $T$. sordida populations from Bolivia and Brazil at the macrogeographical level (inferred based on molecular markers, e.g. [10-13]), very little is known about small-scale triatomine dispersal (e.g. $[14,15])$.

Information on triatomine dispersal capabilities at the micro-geographical level is of fundamental importance concerning the development of effective vector control strategies. The distance between the sylvatic and the domestic habitats seems to be a key factor that governs the success of the insect's dispersive process [16, 17]. Surely, the ability of triatomine bugs to move (either by flight or simply crawling) within the peridomestic area and eventually invade and colonize human dwellings is of special interest [18].

Although survival rates and size estimates of natural populations are important topics to consider when evaluating transmission intensity, both have, to date, received little attention. The generation of reliable information on the abundance of triatomine populations is of great relevance as it provides estimates of recrudescent populations thus allowing for the evaluation of the effectiveness of vector control campaigns. The dispersal of T. sordida, for instance, has been studied in specific landscapes such as salt-flats (Salinas), or with the aid of experimental hen houses $[19,20]$. The few estimates available suggest some individuals may present a long flight, with collection $>100 \mathrm{~m}$ from release point $[19,20]$.

The most effective technique for estimating insect dispersal capabilities, survival rates and population sizes, at the microgeographic scale, is the mark, release and recapture (MRR) method. It requires, however, that the long-lasting markers do not affect insect behaviour or survival, and also that released insects become randomly mixed within the local native population [21].

Because very little is known regarding the ability of anthropophilic bugs to disperse over small areas, we address this issue by focusing our investigation on the specific area referred to as the peridomicile. It is defined as the existing space situated in between the sylvatic and the domestic areas. The peridomicile is of particular epidemiological relevance as it is believed to serve as the liaison between sylvatic and domestic transmission cycles. Here, the dispersal capability of adult $T$. sordida within the peridomestic area of a rural Brazilian household was evaluated via mark-release-recapture assays. Furthermore, survival rates and size estimates of natural populations were analyzed.

\section{Methods}

Study area

The study was conducted in one specific rural area in Posse, Goiás State, Brazil. This district is located at approximately $320 \mathrm{~km}$ from the capital, Brasília (Fig. 1). It encompasses an area of $2058.03 \mathrm{~km}^{2}$ and supports a population of approximately 35,000 inhabitants [22]. The vegetation is that of the Cerrado, a vast tropical plateaued savanna area that is the second largest Brazilian biome. It is a typical poor rural area with simple houses made of bricks and clay roof tiles. It is common to see peridomestic structures such as chicken coops (CC), horse corrals $(\mathrm{HC})$, pigsties, and corn storage units in the region.

The household chosen for the experiment had two peridomestic annexes: a $\mathrm{CC}$ and an $\mathrm{HC}$. The $\mathrm{CC}$ was $1.7 \mathrm{~m}$ high with an area of approximately $7.0 \mathrm{~m}^{2}$. Walls made with old timber were covered by an asbestos roof. The CC offered refuge to about eight chickens. A T. sordida colony was present. A rat nest was detected outside of one of the walls in an old tire with ragged cloth inside which was negative for the presence of triatomines. The $\mathrm{HC}$ was $3.5 \mathrm{~m}$ high with an area of approximately $90.0 \mathrm{~m}^{2}$ covered by a clay tile roof that provided shelter for two horses. Inside the $\mathrm{HC}$ there were small piles of timber where $T$. sordida specimens were found.

\section{Triatoma sordida field-collection and laboratory rearing}

Triatomine collection was performed during five separate days from early April to late May of 2014 in 44 different rural properties in nine villages located on the surroundings of Posse district. The main objective of this field collections was to obtain enough insects to start a laboratory colony for further MRR experiments. Insects were captured manually with the aid of metal tweezers, from 9:00 am until 4:00 pm in peridomestic structures such as $\mathrm{CC}, \mathrm{HC}$, pigsties and corn storage units. 


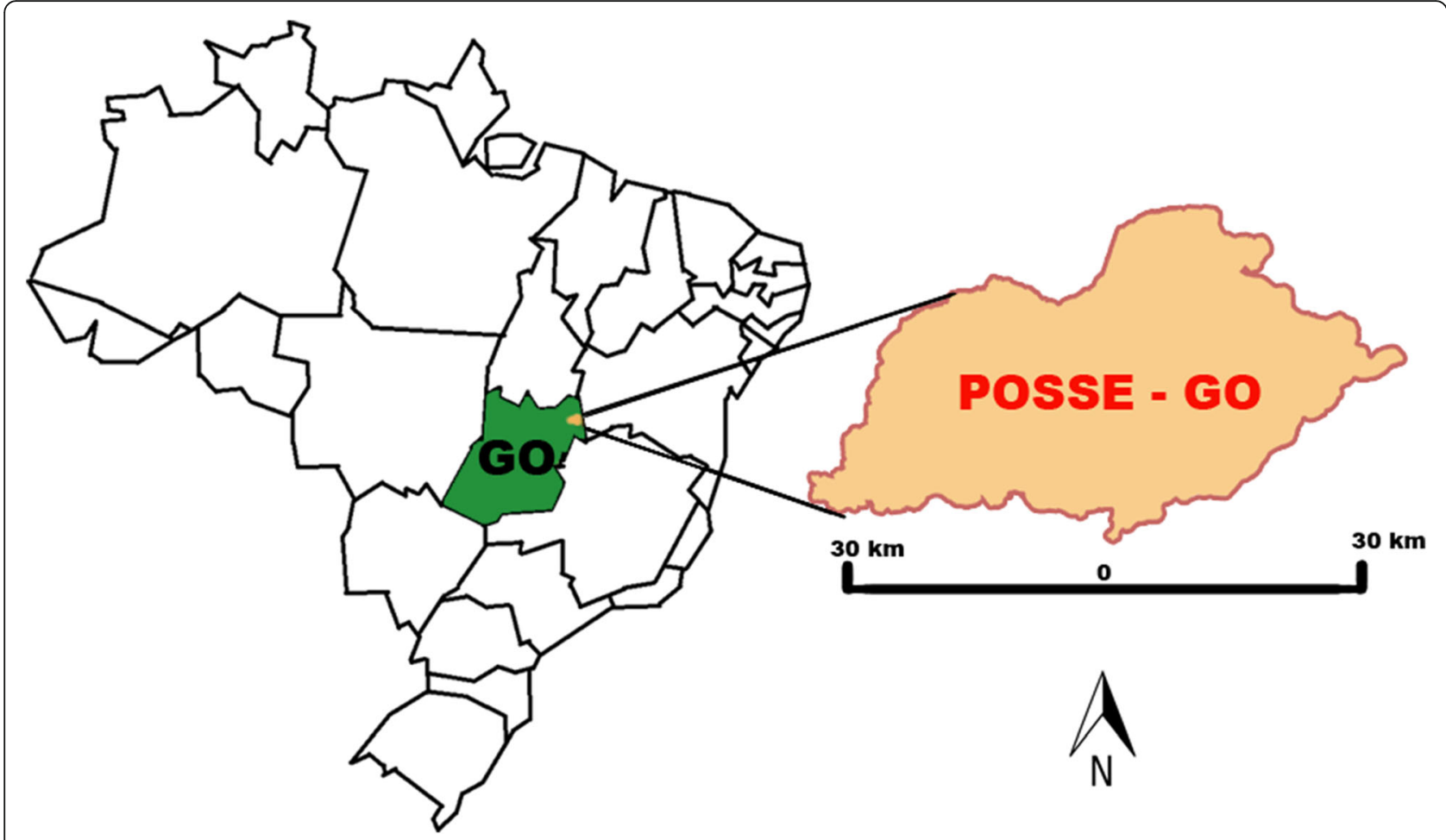

Fig. 1 Location of the Municipality of Posse, Goiás State (GO), Central-West Region of Brazil

Collected specimens were transported to the Laboratory of Medical Parasitology and Vector Biology of the University of Brasília in $50 \mathrm{ml}$ falcon tubes. At the laboratory, specimens were morphologically identified [23], placed in appropriate cages, and kept in the insectary (mean temperature of $30 \pm 2{ }^{\circ} \mathrm{C}$, with no humidity control) until a minimum of 210 adult insects (70 per release point) were obtained for the MRR experiments (i.e. adding the number of collected adults to fourthand fifth-instars that molted into adulthood while in the insectary). Insects were fed on chickens every 15 days for 30-40 min.

\section{Mark, release and recapture (MRR) assays}

Because very little is known regarding the capacity adult triatomines have in terms of small-scale dispersal (and our ability to recapture them), we adopted a simple strategy to assess insect movement that started by releasing marked specimens at a very close distance $(2,5$ and $10 \mathrm{~m}$ ) from its most likely destination point: the chicken coop. This assumption was based on historical data on triatomine bug surveillance conducted by local technicians and described in detail by Rossi et al. [24]. Evaluation of dispersal through longer distances was guaranteed by the presence of another manmade structure, the horse corral (HC), located farther away from the first three release points.
Triatoma sordida adults were marked with fluorescent dust (DayGlo Color Corp, Cleveland, USA) of different colors. Instead of using the dust dry, approximately $5 \mathrm{mg}$ of each color was mixed in $2 \mathrm{ml}$ of water to generate a thick liquid dye to be painted on the insect's pronotum with the aid of a fine brush (Fig. 2). The use of fluorescent dust to mark insects is a common approach on MRR studies since the topic application does not seem to affect insect survival [25].

A total of three marks, release and recapture (MRR) experiments were conducted to estimate triatomine movement, survival and abundance. In the first experiment, 210 adults were released from three points (70 from each) along with a straight line at the distances of $2 \mathrm{~m}$ (marked in blue), $5 \mathrm{~m}$ (orange), and $10 \mathrm{~m}$ (green) from the CC. These points were also 35,32 and $27 \mathrm{~m}$ away respectively from the $\mathrm{HC}$ (Fig. 3).

The first recapture was conducted in the morning 15 days after the release and both structures (CC and $\mathrm{HC}$ ) were inspected for the presence of marked T. sordida. The inspection was carried out by three health agents during $60 \mathrm{~min}$ in each recapture site. Both marked and newly captured (unmarked) adults received a purple dot on the pronotum and were released at dusk along a second transect $10 \mathrm{~m}$ away from $\mathrm{CC}$ and $46 \mathrm{~m}$ from $\mathrm{HC}$. This was done to increase the release distances from the two peridomestic structures while remaining inside the peridomicile (Fig. 3 ). 


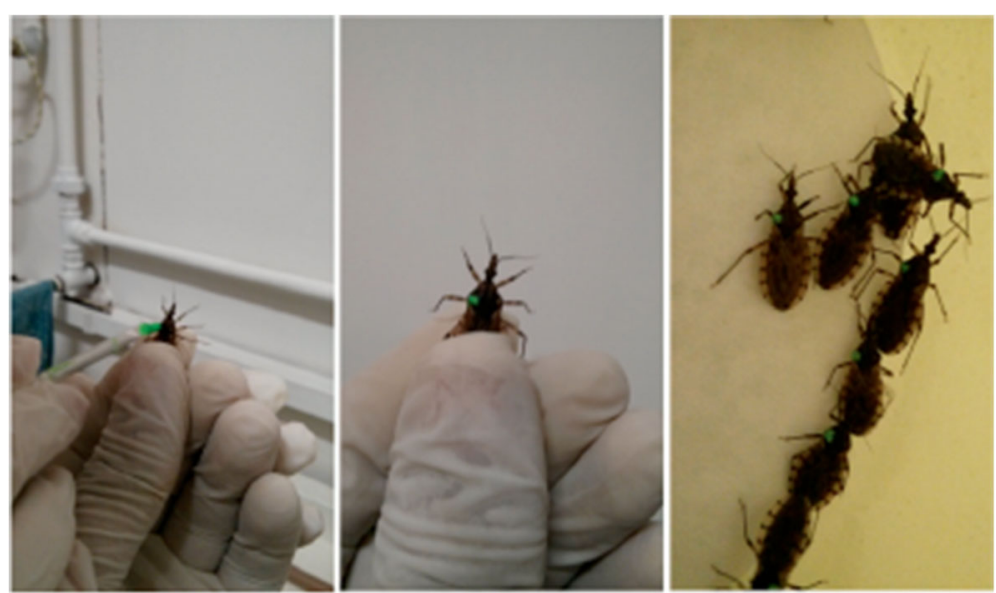

Fig. 2 Process of painting the insect's pronotum. Different colors were used to determine different points and dates of release

Thirty days post-release we performed the second recapture event. Captured insects included specimens from the first and second releases, as well as new unmarked adults. All specimens received a pink mark on the pronotum and were released on the evening of the same day along with a third transect $20 \mathrm{~m}$ away from $\mathrm{CC}$ and $56 \mathrm{~m}$ from $\mathrm{HC}$. The third and last recapture event were performed 45 days after the first release. By using different colors to mark insects, we were able to determine the exact day of release and distance travelled for every recaptured individual. All collected bugs were examined under UV light to determine whether there was a marker and if positive which color.

\section{Statistical analysis}

We describe the capturing process as a Bayesian model. Each capture is described by a sequence of events, an MRR history, depending on the release times and capture occasion. The capture site is also part of the capturing history as a local variable $l$ (dichotomous variable: $\mathrm{HC}, \mathrm{CC}$ ). The capture probability is described by $p_{i, j}$ of history $i$ and sex $j$ (female/male). We model $p_{i, j}$ such that $\log \left(p_{i, j}\right)=\beta_{0, j}+\beta_{1, j} l_{i}+\beta_{2, j} d_{i}$, where $d_{i}$ is the distance

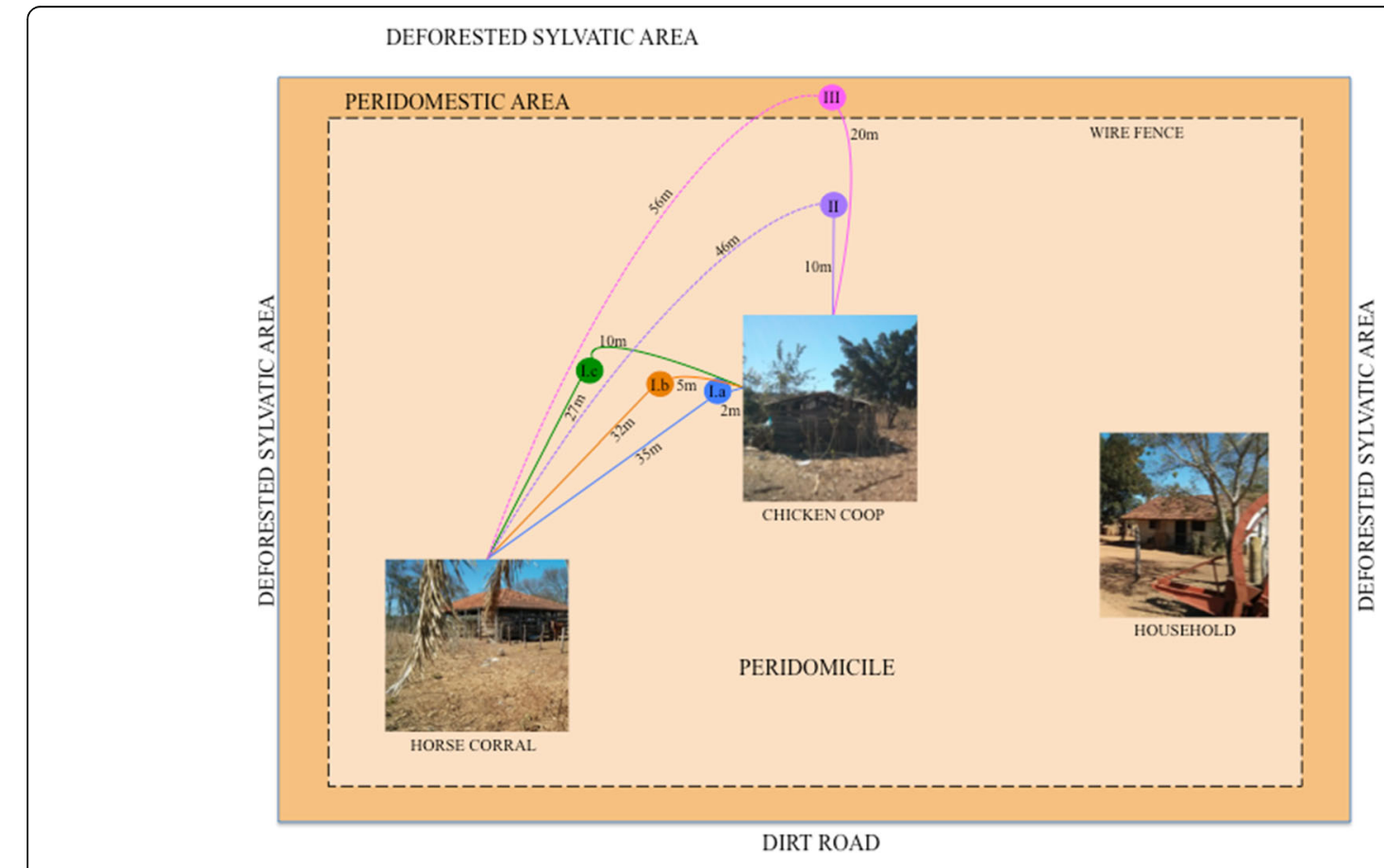

Fig. 3 Area of study, release points, peridomicile structures and distances tested. I, first release event; II, second release event; III, third release event 
from releasing point to the capture site for history $i, \beta_{0, j}$ is an intercept, and $\beta_{1, j}$ and $\beta_{2, j}$ are coefficients associated with local variable and distance, respectively. The few histories involving multiple recaptures contain multiple distance values associated with distance from each recapture to its releasing point. The number of captures described by history $i$ for sex $j$ is defined by $N_{i, j}$ $\sim \operatorname{Binomial}\left(R_{i, j}, p_{i, j} \phi^{n_{i}}\right)$, where $R_{i, j}$ is the number of releases, $\phi$ is the probability of survival during a 15-day period, and $n_{i}$ is the number of surviving intervals.

Four different Bayesian models were tested. The first and simplest model (M0) considers survival rates and distance to capture location only. The second model (ML) increases in complexity by adding information on the collection location (whether insects were captured in $\mathrm{CC}$ or HC). The third model (MS) replaces "collection location" information with that on the sex of recaptured specimens. Finally, the fourth model (MLS) incorporates all parameters mentioned above (i.e. distance, survival rates, capture location, and sex). Model MS had the lowest deviance information criterion (DIC) and was therefore used in three of the four analyses performed. The MSL model was also used to specifically evaluate the likelihood of insects reaching either the CC or the $\mathrm{HC}$.

Our Bayesian models are described using BUGS language $[26,27]$. We use these models to run Markov Chain Monte Carlo simulations (MCMC), and as a result, to obtain posterior distributions for $\beta$ parameters. Such distributions permit us to obtain estimates for the $\beta$ parameters given our observations in the field, which explains how capturing probability is affected as release distance increases and the capture site varies $(\mathrm{HC} / \mathrm{CC})$. We used prior distributions $\beta_{2, j} \sim \operatorname{Normal}(0,100), \beta_{1, j} \sim$ $\operatorname{Normal}(0,100)$, exp. $\left(\beta_{0, j}\right) \sim \operatorname{Beta}(2,2)$.

Abundance estimates were obtained with the MRR data generated herein using the deterministic models of Fisher-Ford and Lincoln [25, 28-30]. These estimates were compared with the ones obtained via the chosen Bayesian model (Model MS).

\section{Results}

A total of 44 peridomestic structures were inspected on the outskirts of Posse, and 30 (68.2\%) were positive for the presence of $T$. sordida. A total of $583 T$. sordida were collected (368 adults, with 232 males and $136 \mathrm{fe}$ males, $143 \mathrm{~N} 5,42 \mathrm{~N} 4,8 \mathrm{~N} 3,2 \mathrm{~N} 2$ and $20 \mathrm{~N} 1$ ), with an average of 19.4 specimens per positive premise.

Of the 210 marked specimens released at the first MRR event (day 1), 16 (7.6\%) were recaptured on day 15. A total of ten insects (eight males and two females) were collected in CC, whereas 6 (one male with an orange mark and thus released at $5 \mathrm{~m}$ away from $\mathrm{CC}$, and four males and one female with a green mark released $10 \mathrm{~m}$ away from CC) were found in HC (Table 1). Therefore, $37.5 \%$ of the marked individuals recaptured were collected at $\mathrm{HC}$, which is $27-32 \mathrm{~m}$ away, instead of at the $\mathrm{CC}$ located at 5-10 $\mathrm{m}$ from the release points (Fig. 2, Table 1). Additionally, ten new (unmarked) specimens were collected at CC.

In the second MRR event, 25 individuals received a purple mark ( 15 of them received the second mark, and 10 new specimens were marked for the first time) and were released on day 15 at 10 and $46 \mathrm{~m}$ away from CC and $\mathrm{HC}$, respectively. On the morning of day 30 , we recaptured six marked individuals, four of them (three males and one female) from the first release (day 1) and therefore captured for the first time; two recaptured for the second time, and 18 unmarked insects (Table 1). During the second recapture event, all triatomine bugs were recovered in CC.

In the third MRR event, 23 individuals (six already recaptured in the first and second MRR and 18 new specimens) received a pink mark and were released at 20/56 m away from CC/HC (Table 1). At this point, there were triatomine bugs in the field with one, two or three markers, which allowed us to determine the distance marked individuals were released and for how long they survived in the field. A total of five marked insects were recaptured on day 45 , including two males from the first release (day 1 ), one released at $2 \mathrm{~m}$ (blue mark) and another at $10 \mathrm{~m}$ (green mark). The other three triatomines were marked with a pink dot and thus released at $20 \mathrm{~m}$ on the third MRR event (day 30). No new individuals were captured at this time.

Recapture likelihood seems to be sex-biased as females were found more often at $\mathrm{CC}$ than at $\mathrm{HC}$. The ratio $\mathrm{HC} / \mathrm{CC}$ for male recapture is close to 1 with a wide distribution, indicating that males, instead, appear not to have a particular preference for either peridomestic structure (Fig. 4a). Recapture probability showed an inversely proportional relationship to distance (from release to collection sites). Capture probability decreases by factors given in Fig. 4b for both males and females. This analysis shows that distance is a limiting factor for triatomine dispersal, especially for females. Although subject to a greater predation risk by moving longer distances to reach $\mathrm{HC}$, no statistical difference was detected between male/female survival probabilities (Fig. 4c).

Based on the results seen in Fig. 4b, a graph was generated to depict the probabilities associated with the ability of $T$. sordida to reach both peridomestic structures within distances of up to $100 \mathrm{~m}$. Nonetheless, there is still a low possibility of these insects reaching $\mathrm{CC}$ or $\mathrm{HC}$ even at greater distances.

The probability of reaching a peridomestic structure when at a distance of, say, $20 \mathrm{~m}$ is much higher for 
Table 1 Color identification and number of T. sordida adults used in three MRR experiments with respect to release distances from the chicken coop (CC) and horse corral ( $\mathrm{HC})$, performed within a 45 day period

\begin{tabular}{|c|c|c|c|c|c|c|c|c|c|}
\hline Event & Mark $^{a}$ & Release & $\begin{array}{l}\text { Distance/ } \\
\text { CC (m) }\end{array}$ & $\begin{array}{l}\text { Distance/ } \\
\mathrm{HC}(\mathrm{m})\end{array}$ & $\begin{array}{l}\text { Male/ } \\
\text { female }\end{array}$ & Recapture & $\begin{array}{l}\text { Marked male/ } \\
\text { female CC }\end{array}$ & $\begin{array}{l}\text { Marked male/ } \\
\text { female HC }\end{array}$ & $\begin{array}{l}\text { Unmarked male/ } \\
\text { female wild }\end{array}$ \\
\hline \multirow[t]{3}{*}{ First MRR } & B & Day 1 & 2 & 35 & $40 / 30$ & Day 15 & $2 / 1$ & - & \\
\hline & O & Day 1 & 5 & 32 & $40 / 30$ & Day 15 & $5 / 1$ & $1 /-$ & $3 / 7$ \\
\hline & G & Day 1 & 10 & 27 & $40 / 30$ & Day 15 & $1 /-$ & $4 / 1$ & \\
\hline \multirow[t]{7}{*}{ Second MRR } & B & Day 1 & 2 & 35 & - & Day 30 & $2 / 1$ & - & \\
\hline & $\mathrm{O}$ & Day 1 & 5 & 32 & - & Day 30 & $-/ 1$ & - & \\
\hline & G & Day 1 & 10 & 27 & - & Day 30 & - & - & \\
\hline & P & Day 15 & 10 & 46 & $3 / 7$ & Day 30 & - & - & $13 / 5$ \\
\hline & $\mathrm{B}, \mathrm{Pu}$ & Day 15 & 10 & 46 & $2 / 1$ & Day 30 & - & - & \\
\hline & $\mathrm{O}, \mathrm{Pu}$ & Day 15 & 10 & 46 & $6 / 1$ & Day 30 & $1 /-$ & - & \\
\hline & $\mathrm{G}, \mathrm{Pu}$ & Day 15 & 10 & 46 & $4 / 1$ & Day 30 & $-/ 1$ & - & \\
\hline \multirow[t]{15}{*}{ Third MRR } & B & Day 1 & 2 & 35 & - & Day 45 & $1 /-$ & - & - \\
\hline & $\mathrm{O}$ & Day 1 & 5 & 32 & - & Day 45 & - & - & - \\
\hline & G & Day 1 & 10 & 27 & - & Day 45 & $1 /-$ & - & - \\
\hline & P & Day 15 & 10 & 46 & - & Day 45 & - & - & - \\
\hline & $\mathrm{B}, \mathrm{Pu}$ & Day 15 & 10 & 46 & - & Day 45 & - & - & - \\
\hline & $\mathrm{O}, \mathrm{Pu}$ & Day 15 & 10 & 46 & - & Day 45 & - & - & - \\
\hline & $\mathrm{G}, \mathrm{Pu}$ & Day 15 & 10 & 46 & - & Day 45 & - & - & - \\
\hline & $\mathrm{Pi}$ & Day 30 & 20 & 56 & $12 / 5$ & Day 45 & $2 /-$ & - & - \\
\hline & $\mathrm{Pu}, \mathrm{Pi}$ & Day 30 & 20 & 56 & - & Day 45 & & - & - \\
\hline & $\mathrm{B}, \mathrm{Pi}$ & Day 30 & 20 & 56 & $2 / 1$ & Day 45 & $-/ 1$ & - & - \\
\hline & $\mathrm{O}, \mathrm{Pi}$ & Day 30 & 20 & 56 & $-/ 1$ & Day 45 & - & - & - \\
\hline & $\mathrm{G}, \mathrm{Pi}$ & Day 30 & 20 & 56 & - & Day 45 & - & - & - \\
\hline & $\mathrm{B}, \mathrm{Pu}, \mathrm{Pi}$ & Day 30 & 20 & 56 & - & Day 45 & - & - & - \\
\hline & $\mathrm{O}, \mathrm{Pu}, \mathrm{Pi}$ & Day 30 & 20 & 56 & $1 /-$ & Day 45 & - & - & - \\
\hline & $\mathrm{G}, \mathrm{Pu}, \mathrm{Pi}$ & Day 30 & 20 & 56 & $-/ 1$ & Day 45 & - & - & - \\
\hline
\end{tabular}

$B$ blue, $O$ orange, $G$ green, $P$ u purple, $P i$ pink

aThe abbreviations on the "Mark" column refer to the color insects were marked

males (approximately 60\%), than for females (40\%) (Fig. 5). This suggests T. sordida males are more likely to contribute as potential colonizers of the peridomestic environment.

Estimates based on the deterministic Fisher-Ford model were all within the credibility interval of the Bayesian method (Model MS). On the other hand, estimates for the Lincoln model lay outside the Bayesian credibility interval (e.g. the credibility interval during the second recapture pointed to 18-136 males, whereas the Lincoln estimate was 780 males; Table 2). A great rise in abundance estimates was observed between the first and second recapture events (Table 2). It seems unlikely that this discrepancy resulted from real population size increase, but rather could be due to the collection of previously uncaptured "resident" triatomines during the second recapture event.

\section{Discussion}

The results presented here on the dispersal capabilities of adult Triatoma sordida specimens in the peridomicile of a rural central Brazil household were obtained using MRR. With the development of an efficient marking system that used long-lasting marks of different colors that could be systematically added to the pronotum of recaptured insects, we were able to generate relevant new information on the dispersal and dynamics of a peridomestic $T$. sordida population. This sort of information, i.e. triatomine dispersal capabilities on a microgeographical scale, although of obvious epidemiological relevance, seems to have remained elusive to investigators throughout the years.

The most salient feature of this study was the determination that, in a 45-day interval, adult $T$. sordida specimens released in the peridomestic area of a typical 

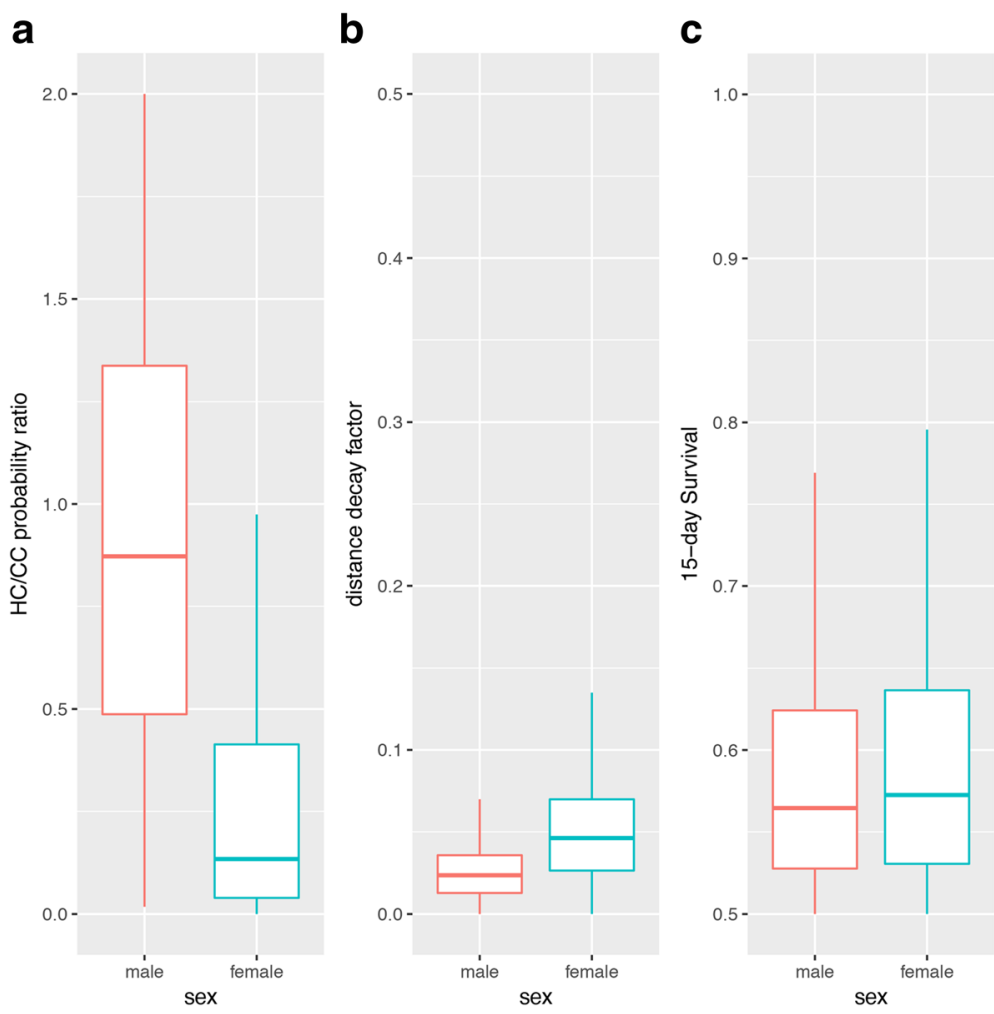

Fig. 4 Bayesian models. a Capture probabilities for horse corral/chicken coop ratios for both males and females (Model MSL). b Effect of distance between release and recapture locations on the probability of $T$. sordida reaching either peridomestic structure (Model MS). c Male and female survival probabilities for three 15-day periods (Model MS)

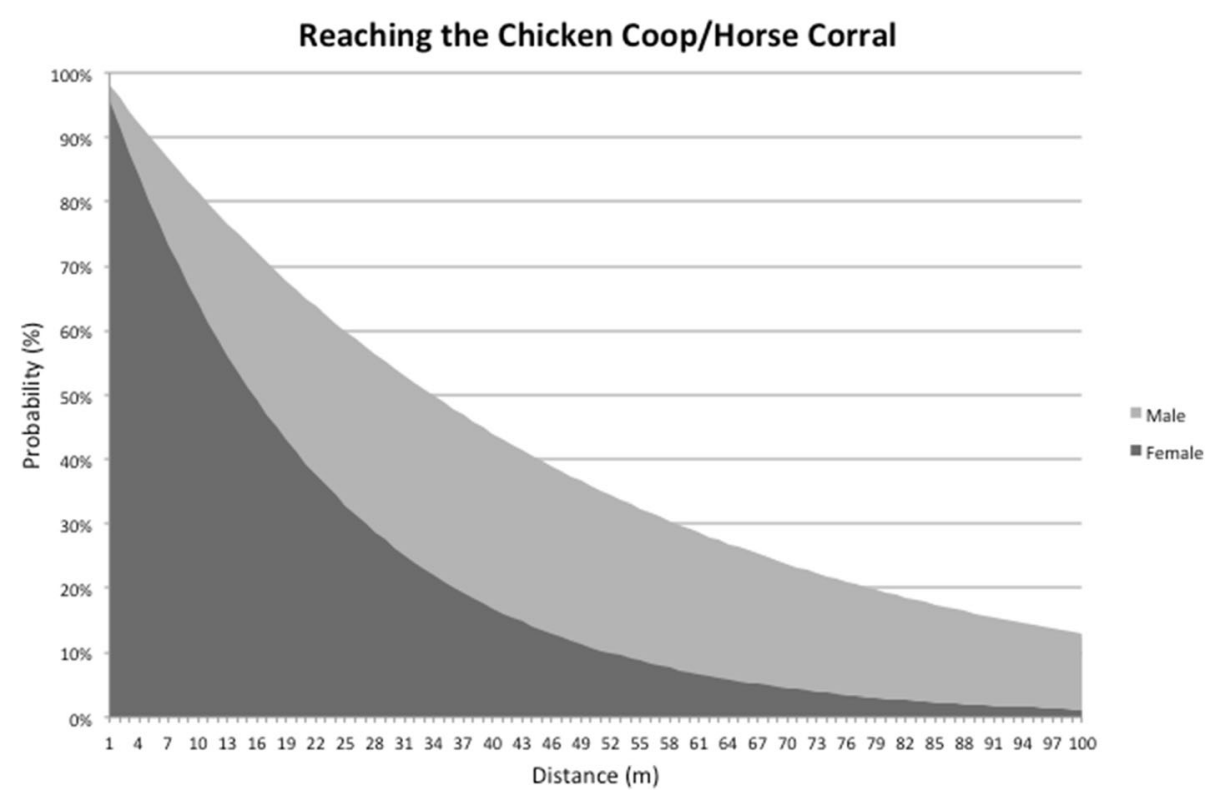

Fig. 5 Probability of Triatoma sordida adults of reaching any of the two peridomestic structures, the chicken coop or the horse coral, for different distances 
Table 2 Relative abundance of Triatoma sordida based on the Bayesian method (Model MS) and the deterministic Fisher-Ford and Lincoln methods

\begin{tabular}{|c|c|c|c|c|c|}
\hline \multirow{2}{*}{$\begin{array}{l}\text { Abundance estimate } \\
\text { Population/Occasion (first or second recapture) }\end{array}$} & \multicolumn{3}{|c|}{ Bayesian method } & \multirow{2}{*}{$\begin{array}{l}\text { Fisher-Ford } \\
\text { Estimate }\end{array}$} & \multirow{2}{*}{$\begin{array}{l}\text { Lincoln } \\
\text { Estimate }\end{array}$} \\
\hline & Mean & Median & Credibility interval & & \\
\hline Male/first recapture & 29 & 24 & $10-73$ & 32 & 105 \\
\hline Male/second recapture & 53 & 45 & $18-136$ & 70 & 780 \\
\hline Female/first recapture & 12 & 9 & $4-41$ & 40 & 135 \\
\hline Female/second recapture & 21 & 15 & $6-69$ & 40 & 450 \\
\hline
\end{tabular}

rural house in central Brazil, are capable of actively dispersing across distances of up to $32 \mathrm{~m}$. The cues defining the orientation of such dispersal are unclear as, contrary to the expectation that insects would be more prone to move towards the closer $\mathrm{CC}$, some dispersed further and in a different direction to achieve the more distant HC. This is an important finding as it challenges the belief that $T$. sordida has a remarkable preference for avian hosts.

The establishment of distances, in a given period, within which insect colonization (or recolonization) are likely to occur is fundamental for the understanding of Chagas disease epidemiology and constitute a major step forward towards long-term sustainable vector control interventions.

The observation that there is an apparent discontinuity in the capture success, in a 45-day period, at the distance of $32 \mathrm{~m}$ is of special epidemiological interest (assuming no insects flew beyond the maximum distance of $56 \mathrm{~m}$, see below). This finding is corroborated by the results of statistical models applied to the data obtained. The major focus of all multinational Chagas disease control initiatives launched to date has relied on the spraying of infested houses and peridomestic structures with residual insecticides [31]. However, sylvatic populations of triatomine bugs may migrate and re-colonize peridomestic structures soon after control activities [32-34].

The evaluation of $T$. sordida infestation in 406 rural households of Southeast Brazil led to the collection of 772 insects before insecticide spraying (98\% in the peridomicile [35]). A similar number of insects were captured in the two collections performed after spraying (7 and 12 months afterwards). It was observed that $62.9 \%$ of captured peridomestic $T$. sordida was located near the sylvatic area $(12-300 \mathrm{~m})$. Authors attributed the finding of high numbers of specimens after spraying for local insect survival and immigration from sylvatic areas [35]. Although informative, the lack of utilization of a marking technique prevented the authors from drawing more objective conclusions based on the data obtained. In addition, it seems that $T$. sordida's reduced dispersal capability would have precluded dispersal over larger areas. Therefore, it would be more plausible to suppose that insects collected after spraying constituted a recrudescent population composed of surviving individuals.
Direct MMR observation revealed 27 and $32 \mathrm{~m}$ as maximum travelled distance towards a peridomestic structure by females and males (one individual each), respectively. As expected, the probability of reaching either $\mathrm{CC}$ or $\mathrm{HC}$ is strongly dependent on distance. Artificial CCs placed directly in the sylvatic environment became readily infested by wild $T$. sordida populations [19]. Therefore, one practical initiative to reduce the contact rate between human hosts and triatomine bugs would be to construct peridomestic structures as far as possible from the sylvatic environment. Although our study only focused on the peridomestic area, it is reasonable to assume that there is where any new migrant will land if, for instance, it flies in from the sylvatic habitat. In this scenario, the peridomestic structures could act as "stepping-stones" towards any domestic structure. The greater the distance between these three areas (sylvatic environment, peridomestic structures, domestic structure), the lower the likelihood of domestic colonization. Following this line of reasoning, Fig. 5 shows, for example, that if positioned at least $55 \mathrm{~m}$ away, the probability of colonizing CC or HC drops to less than $30 \%$ for males and $10 \%$ for females.

Historical data regarding triatomine movement is based on a variety of marking methods, capturing techniques and data analysis, which compromise the direct comparison of results generated. In general, limited evidence has been produced with regard to the active dispersal capabilities of these insects, with most available data focusing on vector flight capacity. Gómez-Núñez [36] was one of the first to address the issue of triatomine micro-geographical dispersal and communication between sylvatic and domestic transmission cycles. By internally marking specimens of Rhodnius prolixus with gold-covered $\mathrm{CO}_{60}$ wire tags and tracking them with Geiger and scintillation counters, he observed the movement between palm trees to houses in rural Venezuela. During 40 days, $R$. prolixus dispersal was motivated mainly by starvation and did not exceed $15 \mathrm{~m}$. Besides, migration seemed to be unidirectional, from palms towards houses [36]. A recent study [37] suggests through mathematical models that the closer the palm of the house, the greater is the chances of it being visited by $R$. prolixus. 
Schofield et al. [20] carried out an MRR experiment with $T$. sordida adults in salt-flats (salinas) of Argentina aiming to determine flight dispersal behaviour. The majority of released insects were not recaptured, suggesting dispersal capability superior to $200 \mathrm{~m}$ on that specific landscape. Lehane and Schofield [38] performed MRR experiments with fluorescent marked $T$. infestans males and observed that bugs were able to disperse by active flight for more than $100 \mathrm{~m}$ in field sites from Brazil and Argentina. As in Schofield et al. [20], both experiments focused on flight initiation with use of a brick platform to help trigger take-off. The additional stimulus was provided by kerosene lamps as attraction points (only for the latter study).

Our study should not be directly compared with these important earlier investigations. They aimed at determining insect dispersal by flight in a scenario of "fleeing from an inhospitable environment (i.e. salt flats) with the aid of a launching platform". Our results should rather be interpreted as "having escaped from a condition of hardship in the wild, such as the described above, and successfully landing in a peridomestic area, what do adult T. sordida do?"

Could the insects have dispersed (flown) further than the maximum distance of $56 \mathrm{~m}$ investigated here? Possibly, although this issue was beyond the scope of the present work. Nonetheless, available evidence suggests that in the absence of a launching platform adult $T$. infestans will not take-off spontaneously from the ground level as observed by the lack of adults to overcome a physical barrier and return into experimental huts [39]. Moreover, Forattini et al. [19] demonstrated that although wild $T$. sordida will readily invade and colonize experimental CCs in both deforested and pasture areas of the Cerrado, dispersal in the opposite direction was negligible: only one insect out of 172 flew back into the sylvatic area. This indicates that $T$. sordida will likely disperse toward food and shelter and not away from it [40].

We attempted to replicate the natural conditions seen in rural Cerrado areas as much as possible by choosing a specific site that had two natural sources of attraction for triatomines: a CC and an HC. Therefore, we believe that the T. sordida we released in this particular peridomicile most likely achieved the $\mathrm{CC}$ and HC crawling, since insects were monitored for $10 \mathrm{~min}$ after release on the ground at dusk and none started flight.

There is a large body of work on the estimation of abundance, survivorship and other important population descriptors for wild animals [41]. Many methods, however, face limitations when applied to the analysis of vector MRR data where specimens are individually marked and often recaptured multiple times [42]. The experimental design used here, notably the use of a new marker color for different release points and events allowed for important estimates such as (i) capture probability as a function of distance to either $\mathrm{HC}$ and $\mathrm{CC}$, and (ii) triatomine survivorship, to be made.

The MRR method, as almost all experimental techniques, is not perfect and will present shortcomings in certain situations. In our case, one particular limitation was the low recapture rate (which was nonetheless still within the range seen for other vector groups such as mosquitoes, e.g. [42, 43]). Dispersal from a central point will lead inevitably to what is known as "dilution effect" where individuals will spread out over a progressively greater area and thus become more difficult to recapture. We attempted to circumvent such challenge by focusing our searches solely on the two peridomestic structures available, the $\mathrm{CC}$ and $\mathrm{HC}$.

Knowledge of vector survival is key for the estimation of how long an infected vector may transmit a pathogen to a susceptible host. Our survival model showed that there is no difference in survival rates between males and females during a 15-day interval. Surprisingly, results indicate that $T$. sordida males disperse further and thus may colonize the peridomestic structures more effectively than females. Therefore, evidence suggests our paper is the first to demonstrate that sex per se can influence $T$. sordida vectorial capacity.

Triatoma sordida abundance estimates for the first two recapture events show that the number of adults of both sexes significantly increased in each 15 -day period according to the Bayesian, Lincoln and Fisher-Ford methods (excluding Fisher-Ford estimates for females). This sudden increase in population size is unlikely to be real, but rather reflect the collection of previously uncaptured wild insects on the following recapture event. Among the methods used to estimate T. sordida population size, the Lincoln method gave discrepant results since they pointed to a 7.4-fold increase in male population size in a 15-day period. A possible explanation for the discrepancy of the Lincoln method is that survival probability was not considered, only numbers of released and recaptured individuals.

\section{Conclusions}

The implementation of MRR to estimate dispersal capability of triatomine vectors can significantly improve vector control strategies by determining, for instance, the distance within which wild insects are more likely to colonize the peridomestic structures such as $\mathrm{CC}$ or $\mathrm{HC}$. Triatoma sordida showed a dispersal capability, within 45 days, limited to $32 \mathrm{~m}$ from the release point, not being collected beyond this threshold. Therefore, increasing the distance as much as possible between the peridomestic structures and the sylvatic environment, as well as from the peridomestic structures and the 
domicile, seems to be a simple and feasible practice to reduce the contact rate between humans and infected bugs and, by corollary, Chagas disease transmission.

\section{Abbreviations}

CC: Chicken coops; DIC: Deviance information criterion; GO: State of Goiás; HC: Horse corral; MCMC: Markov Chain Monte Carlo; MRR: Mark, release and recapture

\section{Acknowledgments}

We are very grateful to the Health Department of the municipality of Posse-GO, especially to the Vector Control Coordinator, Mr Luis Carlos Nascimento for logistical support, and to the technicians Mr Odeswaldo and Mr Mario for field assistance.

\section{Funding}

This study was supported by the Brazilian National Research Council (CNPq) by a grant conceived to FAM (Call MCTI/CNPq/MS-SCTIE-Decit No 40/2012).

\section{Availability of data and materials}

All data generated or analyzed during this study are included in this published article.

\section{Authors' contributions}

Conceived and designed the experiments: ESD, FAM, RGG and RMF. Performed the experiments: ESD and RGG. Analyzed the data: ESD, DAMV and RMF. Contributed reagents/materials/analysis tools: RGG and FAM. Wrote the paper: ESD, RGG, DAMV, FAM and RMF. All authors read and approved the final manuscript.

\section{Ethics approval}

This project has the approval of the Fiocruz ethical research committee (CEP 346.721) and authorization of the Health Department of the city of Posse. Before the insect releases, Posse health agents helped with the selection of houses with high $T$. sordida infestation allowing for the collection of insects to be released during the study. The owner of the rural property where experiments took place received detailed information on the project objectives and signed a written informed consent form allowing for the release and recapture of insects at his property. We were not granted clearance to search for insects inside the household itself. The blood-feeding of insects at the University of Brasilia on avian hosts were authorized by the UnB Ethical Committee to RGG (approval protocol: 346.721).

\section{Consent for publication}

Not applicable.

\section{Competing interests}

The authors declare that they have no competing interests.

\section{Publisher's Note}

Springer Nature remains neutral with regard to jurisdictional claims in published maps and institutional affiliations.

\section{Author details}

'Laboratório de Transmissão de Hematozoários, Instituto Oswaldo Cruz, Fundação Oswaldo Cruz (IOC/ FIOCRUZ), Rio de Janeiro, Brazil. 'Laboratório de Epidemiologia e Sistemática Molecular, Instituto Oswaldo Cruz, Fundação Oswaldo Cruz (IOC/ FIOCRUZ), Rio de Janeiro, Brazil. ${ }^{3}$ Laboratório de Parasitologia Médica e Biologia de Vetores, Área de Patologia, Faculdade de Medicina, Universidade de Brasília, Campus Universitário Darcy Ribeiro, Brasília, DF, Brazil. ${ }^{4}$ Programa de Computação Científica, Fundação Oswaldo Cruz (PROCC/FIOCRUZ), Rio de Janeiro, Brazil.

Received: 29 September 2017 Accepted: 28 November 2017 Published online: 05 January 2018

\section{References}

1. Burleigh BA, Andrews NW. The mechanisms of Trypanosoma cruzi invasion of mammalian cells. Annu Rev Microbiol. 1995;49:175-200.
2. Bern C, Kjos S, Yabsley MJ, Montgomery SP. Trypanosoma cruzi and Chagas' disease in the United States. Clin Microbiol Rev. 2011;24:655-81.

3. Aguilar HM, Abad-Franch F, Dias JCP, Junqueira ACV, Coura JR. Chagas disease in the Amazon region. Mem Inst Oswaldo Cruz. 2007;102(Suppl. 1): $47-55$.

4. Coura JR. The main sceneries of Chagas disease transmission. The vectors, blood and oral transmissions - a comprehensive review. Mem Inst Oswaldo Cruz. 2015;110:277-82.

5. Requena-Méndez A, Albajar-Viñas P, Angheben A, Chiodini P, Gascón J, Muñoz J, et al. Health policies to control Chagas disease transmission in European countries. PLoS Negl Trop Dis. 2014;8:e0003245.

6. Imai K, Maeda T, Sayama Y, Mikita K, Fujikura Y, Misawaet K, et al. Mother-tochild transmission of congenital Chagas disease, Japan. Emerg Infect Dis. 2014;20:146-8.

7. Dias JC, Ramos AN Jr, Gontijo ED, Luquetti A, Shikanai-Yasuda MA, et al. Brazilian consensus on Chagas disease, 2015. Epidemiol Serv Saúde. 2016;25:7-86.

8. Diotaiuti L, Pereira AS, Loiola CF, Fernandes AJ, Schofield JC, Dujardin JP, et al. Inter-relation of sylvatic and domestic transmission of Trypanosoma cruzi in areas with and without domestic vectorial transmission in Minas Gerais, Brazil. Mem Inst Oswaldo Cruz. 1995;90:443-8.

9. Pereira MH, Gontijo NF, Guarneri AA, Sant'Anna MR, Diotaiuti L. Competitive displacement in Triatominae: the Triatoma infestans success. Trends Parasitol. 2006;22:516-20.

10. Noireau F, Zegarra M, Ordoñez J, Gutierrez T, Dujardin JP. Genetic structure of Triatoma sordida (Hemiptera: Reduviidae) domestic populations from Bolivia: application on control interventions. Mem Inst Oswaldo Cruz. 1999; 94:347-51.

11. Monteiro FA, Jurberg J, Lasoki C. Very low levels of genetic variation in natural peridomestic populations of the Chagas disease vector Triatoma sordida (Hemiptera: Reduviidade) in southeastern Brazil. Am J Trop Med Hyg. 2009;81:223-7.

12. Gonzalez-Britez NE, Carrasco HJ, Martínez Purroy CE, Feliciangeli MD, Maldonado M, López E, et al. Genetic and morphometric variability of Triatoma sordida (Hemiptera: Reduviidae) from the eastern and western regions of Paraguay. Front Public Health. 2014;2:149.

13. Panzera F, Pita S, Nattero J, Panzera Y, Galvão C, Chavez T, et al. Cryptic speciation in the Triatoma sordida subcomplex (Hemiptera, Reduviidae) revealed by chromosomal markers. Parasit Vectors. 2015;8:495.

14. Pérez de Rosas AR, Segura EL, Fichera L, García BA. Macrogeographic and microgeographic genetic structure of the Chagas' disease vector Triatoma infestans (Hemiptera: Reduviidae) from Catamarca, Argentina. Genetica. 2008;133:247-60.

15. Abrahan L, Gorla D, Catalá S. Active dispersal of Triatoma infestans and other triatomines in the Argentinean arid Chaco before and after vector control interventions. J Vector Ecol. 2016;41:90-6.

16. Noireau F, Flores R, Gutierrez T, Abad-Franch F, Flores E, Vargas F. Natural ecotopes of Triatoma infestans dark morph and other sylvatic triatomines in the Bolivian Chaco. Trans R Soc Trop Med Hyg. 2000;94:23-7.

17. Brémond $P$, Salas $R$, Waleckx E, Buitrago R, Aliaga C, Barnabé C, et al. Variations in time and space of an Andean wild population of $T$. infestans at a microgeographic scale. Parasit Vectors. 2014;7:164.

18. Abrahan LB, Gorla DE, Catalá SS. Dispersal of Triatoma infestans and other Triatominae species in the arid Chaco of Argentina: flying, walking or passive carriage? The importance of walking females. Mem Inst Oswaldo Cruz. 2011;106:232-9.

19. Forattini OP, Ferreira AO, Silva EOR, Rabello EX. Aspectos ecológicos da tripanossomíase americana. V - Observações sobre colonização espontânea de triatomíneos silvestres em ecótopos artificiais, com especial referência ao Triatoma sordida. Rev Saúde Públ. 1973;7:219-39.

20. Schofield CJ, Lehane MJ, McEwan P, Catala SS, Gorla DE. Dispersive flight by Triatoma sordida. Trans R Soc Trop Med Hyg. 1991;85:676-8.

21. Southwood TRE, Handerson PA. Ecological methods. 3rd ed. Oxford: Blackwell Science; 2000.

22. Instituto Brasileiro de Geografia e Estatística - IBGE. Available from: http:// cod.ibge.gov.br/2W2ZO. Accessed 25 Sept 2017.

23. Lent $H$, Wygodzinsky P. Revision of the Triatominae (Hemiptera, Reduviidae) and their significance as vectors of Chagas disease. Bul Amer Mus Nat Hist. 1979;163:520-9.

24. Rossi JC, Duarte EC, Gurgel-Gonçalves R. Factors associated with the occurrence of Triatoma sordida (Hemiptera: Reduviidae) in rural localities of central-west Brazil. Mem Inst Oswaldo Cruz. 2015;110:192-200. 
25. Service MW. Mosquito ecology field sampling methods. 2nd ed. London: Chapman \& Hall; 1993.

26. Spiegelhalter DJ, Thomas A, Best NG, Gilks W, Lunn D. BUGS: Bayesian inference using Gibbs sampling. Cambridge: MRC Biostatistics Unit; 1993.

27. Spiegelhalter DJ, Best NG, Carlin BP, van der Linde A. Bayesian measures of model complexity and fit (with discussion). J R Stat Soc B. 2002;64:583-639.

28. Dowdeswell W, Fisher R, Ford E. The quantitative study of populations in the lepidoptera I. Polyommatus icarus rott. Ann Eugenics. 1940;10:123-36.

29. Cianci D, Van Den Broek J, Caputo B, Marini F, Torre AD, Heesterbeek H, et al. Estimating mosquito population size from mark-release-recapture data. J Med Entomol. 2013:50:533-42.

30. Villela DAM, Codeço CT, Figueiredo F, Garcia GA, Maciel-de-Freitas R, Struchiner CJ. A Bayesian hierarchical model for estimation of abundance and spatial density of Aedes aegypti. PLoS One. 2015;10:e0123794.

31. Silveira AC, Dias JCP. O controle da transmissão vectorial. Rev Soc Bras Med Trop. 2011;44:52-63.

32. Abad-Franch F, Palomeque FS, Aguilar HM, Miles MA. Field ecology of sylvatic Rhodnius populations (Hetereptera, Triatominae): risk factors for palm tree infestation in western Ecuador. Tropical Med Int Health. 2005;10: 1258-66.

33. Ceballos LA, Piccinali RV, Marcet PL, Vazquez-Prokopec GM, Cardinal MV, et al. Hidden sylvatic foci of the main vector of Chagas disease Triatoma infestans: threats to the vector elimination campaign? PLoS Negl Trop Dis. 2011;5:e136.

34. Grijalva MJ, Villacis AG, Ocana-Mayorga S, Yumiseva CA, Baus EG. Limitations of selective deltamethrin application for triatomine control in central coastal Ecuador. Parasit Vectors. 2011;4:20.

35. Diotaiuti L, Azeredo BVM, Busek SCU, Fernandes AJ. Controle do Triatoma sordida no peridomicílio rural do município de Porteirinha, Minas Gerais, Brasil. Pan Am J Public Health. 1998;3:21-5.

36. Gomez-Núñez JC. Resting places, dispersal and survival of COs-tagged adult Rhodnius prolixus populations. J Med Ent. 1969;6:83-6.

37. Erazo $\mathrm{D}$, Cordovez J. Modeling the effects of palm-house proximity on the theoretical risk of Chagas disease transmission in a rural locality of the Orinoco basin, Colombia. Parasit Vectors. 2016;18:592.

38. Lehane MJ, Schofield CJ. Field experiments of dispersive flight by Triatoma infestans. Trans R Soc Trop Med Hyg. 1981;75:399-400.

39. Gurevitz JM, Ceballos LA, Kitron U, Gürtler RE. Factors affecting flight initiation of field Triatoma infestans (Hemiptera: Reduviidae) under natural climatic conditions. J Med Entomol. 2006;43:143-50.

40. Schofield CJ. Triatominae-Biology \& Control. West Sussex: Eurocommunica Publications; 1994.

41. Mackenzie DI, Nichols JD, Royle JA, Pollock KH, Bailey LL, Hines JE. Occupancy estimation and modeling: inferring patterns and dynamics of species. Boston: Elsevier; 2006.

42. Villela DAMV, Garcia GA, Maciel-de-Freitas R. Novel inference models for estimation of abundance, survivorship and recruitment in mosquito populations using mark-release-recapture data. PLoS Negl Trop Dis. 2017;11: e0005682.

43. Silver JB. Mosquito ecology: field sampling methods. 3rd ed. New York: Springer; 2008

\section{Submit your next manuscript to BioMed Central and we will help you at every step:}

- We accept pre-submission inquiries

- Our selector tool helps you to find the most relevant journal

- We provide round the clock customer support

- Convenient online submission

- Thorough peer review

- Inclusion in PubMed and all major indexing services

- Maximum visibility for your research

Submit your manuscript at www.biomedcentral.com/submit
Biomed Central 